\title{
SIMILARITY, COHESION, DISTANCING AND FRIENDSHIP QUALITY AMONG ITALIAN AND BOLIVIAN BOYS AND GIRLS: A CROSS NATIONAL COMPARISON
}

\author{
Emanuela Rabaglietti, Maria Fernanda Vacirca, Giulia Zucchetti \\ University of Turin, Italy \\ E-mail: emanuela.rabaglietti@unito.it, \\ mariafernanda.vacirca@unito.it, \\ giulia.zucchetti@unito.it \\ Carmen Camacho \\ University of Tarija, Bolivia \\ E-mail: ccamachot@gmail.com \\ Silvia Ciairano \\ University of Turin, Italy \\ E-mail: silvia.ciairano@unito.it
}

\begin{abstract}
This study aimed to contribute at exploring friendship in children from two different countries, Italy and Bolivia, focusing on the association between specific characteristics of children's friendships, such as similarity, cohesion and distance with friends as represented by the children through drawing, and the perception of their friendship quality. Participants were 100 children (55 Italians and 45 Bolivians) attending primary schools. The two subgroups are balanced for gender and age [Italian girls: $56 \%, N=31$, Bolivian girls $51 \%, N=23$; $M$ age Italian children $=8.09(S D=.74)$ and Bolivian children $M$ age $=7.91(S D=.90)]$. We used children's drawings and self-reported measures to investigate the dyadic characteristics and the quality of their friendship. Results showed that Italian children drawn themselves and their best friend more similar than Bolivian children $[F(1,94)=6.65 ; p<.002]$. There are more conflicts in the friendships of Bolivian children than in the Italian ones $[F(1,98)=7.87 ; p<.006]$. There is a moderation effect of children's nationality on the association between the pictorial friendship features and friendship quality. These preliminary findings highlighted the importance of investigating children's perceptions of friendship, which is a complex and multidimensional phenomenon, taking into account the social and cultural differences.
\end{abstract}

Key words: cohesion, cross-national differences, distancing, friendship quality, similarity.

\section{Introduction}

Children's friendship is a complex and multidimensional phenomenon that develops as children enter primary school when they begin to interact with peers outside the family. During this period some characteristics begin to emerge providing to the children's friendship a role of primary attraction in the investigation of the social development. 
In fact friendship is a very important aspect of socialization, which plays an essential role in child development and adjustment (Selman, 1981; Sullivan, 1953; Youniss \& Smollar, 1985). During middle childhood, friendship changes from a relationship characterized by transitory sharing of activities, as observed during preschool age, to a relationship enhanced by psychological dimensions, as intimacy, help, confidence and trust (Fonzi \& Tani, 1996).

During childhood some interesting gender differences also emerge (Cassibba, Balenzano, \& Elia 2008; Rose \& Smith, 2009; Tani, Rossi, \& Smorti, 2005). Female friendships are characterized by intimacy and help, while mutual actions for fun and also aggressive mechanisms prevail in male friendships (Martin \& Fabes, 2001).

\section{Problem of Research}

Children's friendships have already been studied also in connection to cultural differences. Anthropological and ethnography studies have shown that, effective expression of friendship varies in different cultures according to value orientations and social obligations as well as to the different position of the target group within a specific society (Krappmann, 1996). Nonetheless most of the earlier cross-national research has concentrated on family relationships only (Whiting \& Edwards, 1998).

Respect to peer relationships, some authors showed that the characteristics of friendship are equivalent in different cultures (Argyle, Henderson, Bond, Iizuka, \& Contarello, 1986) while other authors claimed the opposite (Adamopoulos \& Bontempo, 1986; Allan, 1989).

Pinto, Bombi \& Cordioli (1997) highlighted the importance of exploring children's friendship in different countries especially through children's drawings and they showed that there are more similarities than differences regarding friendship among Italian, Bolivian and Lebanese children. In sum, their study supports the fact that some characteristics of friendship are universal.

Nevertheless, it is still interesting to investigate the presence of cross-national differences, which might be ascribed to cultural peculiarities in the processes underlying children's friendships in terms of characteristics of the friend (who is perceived as more or less similar to oneself) and characteristics of the friendship quality (positive, as affect, security and companionship, and negative, as conflict). Specifically, among all the other characteristics of friendship, the present study investigates the associations among similarity, cohesion, and distancing as represented by the children in drawing, and children perception of friendship quality in two countries: Italy and Bolivia.

At a sociological level, according to Hofstede $(1980 ; 1991)$, to a certain extent Bolivia might be considered, at least traditionally, a collectivistic country, that is the group is a priority with respect to the individual. A collectivistic society gives importance at maintaining and strengthening of the group's resources and at the collaboration between the members. However, the diffusion of the Northern-American model in the South-American countries, more or less diffuse and powerful in different countries, might have recently rapidly changed the traditional orientation towards more individualistic direction.

Conversely at a certain extent Italy might be considered an individualistic country because it is addressed at promoting individual satisfaction and achievement of personal autonomy basing on values that encourage competition and enhancement of the potential of the individual (Inghilleri, 2009). More precisely the Italian situation could be considered something in the middle between a typical individualistic Northern-American or Northern- European country and a typical collectivistic traditional society.

Nevertheless other kinds of sources, more proximal and less distal than the general sociological orientation, might affect the attitudes of the people towards social relationships, especially during early stage of development as childhood. Among the most important sources there is certainly the way primary school is organized and the educational style adopted by the teachers towards students.

The Italian school system is traditionally aimed at promoting mutual acceptance, cohesion and integration between children and the teacher are trained to use an authoritative, instead of authoritarian, educational style (Petter 2004; Bonino \& Reffieuna, 2007). Great importance is attributed by the teachers to the team-class working and to the sharing of the resources and capacities between peers. Despite that the fact the major part of the Italian school system promotes unity and collaboration 
among students, in the most recent years and in some school, especially in the North of Italy, some competitive and individualistic educational and learning aspects are again spreading. Also the Bolivian primary schools is moving toward an educational reform in which it is underlined the democratic nature of the education. This reform deals with the importance of adopting an intercultural approach by taking into account the cultural and linguistic diversity among children who live in the Bolivian reality. These objectives are difficult to realize because of the radicalization of some social dynamic that make complex and slow the progress in that direction.

So, these different and changing school orientations and educational styles could strongly affect the way in which children relate to peers and their perception of friendship.

Generally speaking, both boys and girls like to establish friendships with children similar to themselves and that this phenomenon is particularly evident when children make drawings of their friendships (Bombi, Pinto \& Cannoni, 2007; Rabaglietti, Vacirca, Zucchett, \& Ciairano, 2012). Similarity, that regards both factual characteristics, such as age and gender, and psychological aspects, such as attitudes and values (Clark \& Drewry, 1985; Hartup, 1989, 1996), is in fact a condition often soughed for choosing friends (Byrne, 1971; Hartup, 1983). Children seem to search for similarity because it promotes the "social comparison", a kind of psychological process common in childhood (Festinger, 1954). Comparing oneself with the other people is relevant for defining the self and own identity, especially in middle childhood. In fact, to establish a comparison with somebody who is very different from oneself is difficult, while relating to somebody who is similar to oneself is much easier (Laursen \& Hartup, 2002). Cohesion is also a relevant feature of social relationships that relates to their formation and maintenance. Cohesion is an essential aspect of close relationships that refers to the affiliative basis of humans' social life (Berscheid, Snyder, \& Omoto, 1989; Duck, 1988; Kelley et al., 1983). The cohesion between friends is a visible characteristic of friendships that makes the building of social bonds evident among the partners. According to Berndt (1981), the cohesion between friends is necessary for displaying that the relationship exists and is sufficient for a prototypical representation of friendship. It is evident that in order to be friends, a stable link with the partner and the maintenance of one's own identity and personal autonomy and individuality are both necessary (Bombi et al., 1997). So far, the current study takes into account also the distancing between friends, that regards their physical distance. There are gender differences for the distance between friends: girls search for intimacy and both physical and psychological closeness with friend earlier than boys (Tani, Smorti, \& Rossi, 2005). Boys are more likely than girls to differentiate from- and to compete with the others, in order to achieve a powerful social status and individual assertiveness (Berndt, 1982).

Regards cultural characteristics of friendship features, Bombi and colleagues (1997) reported that the children of the Bolivian village are different from all the others groups (Bolivia' town, Italian and Lebanon children) in terms of a greater degree of overall similarity between the figures of the self and of the friend. These authors attributed this finding to the major collectivistic orientation of the Bolivian village group respect to the others. However, little is known about the eventual differences and similarities about the cohesion and the distancing between friends in different countries.

The current study covers this lack and includes also a measure of children's friendship quality. Friendship is an inter-process (Bukowski, Hoza, \& Boivin, 2004) which is based on the characteristics of the friends involved in it: the perception of friend's behavior and of the positive and negative features that characterize the relationship contributes to define it in terms of quality. Quality of friendship has already been showed much more important for adjustment than other aspects of friendships, such as the number of friends or time spent with them (Berndt, 1982; Hartup \& Stevens, 1997). Besides, different feature of friendship quality relate in different ways to adjustment (Berndt, 2002; Bukowski, Hoza, \& Boivin, 1994; Furman, 1996). Generally speaking, children with high quality friendships report high levels of well-being (Berndt, Hawkins, \& Jiao, 2005), school adjustment (Ladd, \& Price, 1987; Tomada, Schneider, de Domini, Greenman, \& Fonzi, 2005), ability to cope with stress (Hartup \& Stevens, 1997) and self-esteem (Bishop \& Inderbitzen, 1995) and less loneliness (Ladd, Kochenderfer, \& Coleman, 1996),

In keeping with these evidences in the present study the children's perception of their friendships both in terms of self-report measures for investigating the general quality of the friendships and drawing for investigating in particular the friendship with the best friend were explored. 
To our knowledge few if any study have already investigated children friendship quality across different countries and its association with the characteristics of friendship expressed through a drawing. Generally speaking, the study of friendships to date has relied primarily on the use of selfreporting measures. The use of only these measures may be difficult with children from the lowest grades of primary school because lexical mastery and understanding of written language might be still limited (Bombi, 1993). Rather, the use of drawing to depict friendship might be convenient until the age of eight years as drawing represents an expressive and qualitative method that is more able than others to access a child's mental representations (Bombi \& Pinto, 1994; Bombi et al., 2007). Besides, although a high level of friendship quality is certainly universally relevant for all the children because it is an important indicator of their social competence, the patterns of relationships between self-report measure and drawing may assume different shapes in different social and cultural contexts. To investigate these cross-national differences may be relevant to individuate the characteristics of friendships that assume greater importance with respect to the others for the social adjustment of the children in each context.

\section{Research Focus}

As anticipated similarity, cohesion and distancing between the drawn figures of the children and their best friends at the dyadic level and the perception of their friendship quality were considered to understand the processes of constructing friendships in two different social and cultural contexts. The similarity between the figures represents a signal of how much the child's drawn friend is perceived to be similar to him/her. More precisely, physical similarity (in terms of height, body, posture, and attribute) between the figures is considered as an expressive way of representing the psychological similarity between friends (Bombi \& Pinto, 1993). Meanwhile, the cohesion/distancing between the figures (in terms of glance/looking away, approaching/moving away, coordinated/independent activity etc.) represent indicators of the bond or of the absence of the bond, between two friends. Unifying the figures from a perceptual perspective and representing the interaction between them offer the chance to show the link between the two partners of a relationship using a graphic representation (Bombi \& Pinto, 1993).

In addition, the children's perception of their friendship quality (in terms of positive features, as companionship, security, and support, and negative features, as friends conflict) through children self-report questionnaire is considered.

In sum, the objectives of this cross-national study are:

1. To investigate how children represent themselves drawing the friendship with their best friend, in terms of similarity, cohesion and distancing in the two countries (Bombi et al, 2007); on the basis of the general sociological orientation, children who grow up in an individualistic society (like Italy) would give importance to the personal affirmation and uniqueness in friendships, for instance as expressed by high levels of distancing, while children from a collectivistic society (like Bolivia) would show high levels of similarity and cohesion. Nevertheless considering the school system of these two countries, children who are raised by their teachers accordingly the principles of prosocial behavior as the Italian ones would be also more likely that their Bolivian mates to perceive themselves very similar and less distant from their friends.

2. To examine how Italian and Bolivian children perceive the quality of their friendship in terms of intimacy, security, help, companionship and conflict (Bukowski, Hoza, and Newcomb, 1994; Fonzi \& Tani, 1996). In keeping with the general orientation of Bolivia society, Bolivian children would attribute more importance than Italian children to the aspects that concern intimacy and affinity in friendship by showing higher level of positive friendship quality. High levels of friend conflict would expect between Italian children. Instead according to the school system of these two countries, children who are educated by their teachers accordingly the principles of cooperation and mutual acceptance as the Italian ones would be also more likely that their Bolivian mater to perceive positive friendship quality and less friends conflict. 
3. To investigate the presence of a moderating effect of country in the relationship between pictorial characteristics of the friendship and the quality of this relationship. Generally speaking, positive pictorial characteristics, as similarity, would relate to the positive features of friendship quality, as intimacy. However, moderation effect of the country in the association between pictorial friendship aspects and features of friendship quality would expect. More precisely on the basis of the different orientation of individualistic and collectivistic societies, positive association between pictorial friendship aspect and friendship quality, such as similarity and intimacy among Bolivian children and an association between distancing and conflict among Italian children would expect. However, taking into account the school system opposite results among Bolivian and Italian children would expect.

\section{Methodology of Research}

\section{Sample of Research}

Since that the drawing task is very complicated to code, a reasonable little sample of children was extracted by two primary schools, one in Italy and one in Bolivia. So far, the participants were 100 children ( 55 of Italy and 45 of Bolivia). The two sub-groups are similar for gender (Italian girls: $56 \%, \mathrm{~N}=31$ and Bolivian girls: 51\%, N=23) and for age [Mean: $8.09($ Standard Deviation $=0.74)$ in Italy and Mean $=7.91$ (Standard Deviation $=0.90$ ) in Bolivia] attending the second and the third grade of two primary schools respectively in Italy and Bolivia.

The study was cross sectional. Regarding the relevant structural indicators both Italian and Bolivian participants appear comparable to the general Italian and Bolivian population (ISTAT [National Institute of Statistics], 2009; Various Authors, 2010 [A COCHABAMBA ME VOI]). A total of $89 \%$ of the Italian children lives with both parents, $7 \%$ with only one parent, and $4 \%$ with others adult. With respect to level of education, $52 \%$ of the fathers and $41 \%$ of the mothers had completed compulsory education, $36 \%$ of the fathers and $48 \%$ of the mothers had completed high school, and $12 \%$ of the fathers and $11 \%$ of the mothers had earned a university degree. With respect to jobs, $19 \%$ of the fathers and $16 \%$ of the mothers worked as managers, entrepreneurs, and professionals; $80 \%$ of the fathers and $58 \%$ of the mothers were white or blue collar workers and/or artisans; and $26 \%$ of the mothers were housewives. Respect to Bolivian participants $66 \%$ live with both mother and father $34 \%$ with one only parent. With respect to level of education, $43 \%$ of the fathers and $53 \%$ of the mothers had completed compulsory education, $45 \%$ of the fathers and $45 \%$ of the mothers had completed high school, and $12 \%$ of the fathers and $2 \%$ of the mothers had earned a university degree. With respect to jobs, $44 \%$ of the fathers and $15 \%$ of the mothers worked as managers, entrepreneurs, and professionals; $56 \%$ of the fathers and $75 \%$ of the mothers were white or blue collar workers and/ or artisans; and $10 \%$ of the mothers were housewives.

\section{Instrument and Procedures}

The study was conducted in two primary schools in north-west Italy and in Bolivia. The study has been approved by both the Ethical Committee at the University of Turin and by the Faculty Council at the University of Tarija, Bolivia. Parents provided informed consent for students to participate in accordance with law and the ethical code of the American Psychological Association, and students assented to participate. Italian and Bolivian students completed the drawing task and the questionnaire, which were administered by trained research staff during classroom time.

Considering the children age, the information about structural social and demographic indicators was collected by the way of a questionnaire that children took home to their parents. A total of $98 \%$ of the Italian families and $97 \%$ of the Bolivian families completed the parent questionnaire and returned it to the school (in a sealed envelope) within the assigned time of one week. The parent questionnaire was completed (1) for Italy by mothers in $60 \%$ of the cases, by fathers in $15 \%$ of the cases, and by both parents in $25 \%$ of the cases, and (2) for Bolivia by mothers in $92 \%$ of the cases, by fathers in $2 \%$ of the cases, and by both parents in $6 \%$ of the cases. There were no differences 
in the study variables between the children whose parents completed the parent questionnaire and those whose parents both Italian (2\%) and Bolivian (3\%) did not. The administration of the drawing task and of the questionnaire (which also included items investigating children's eating habits and daily activities that will not be used in the present study) lasted approximately one hour. Parents' completion of the questionnaire lasted approximately 15 minutes. We did not offer any incentive for participation in the study. However, no Italian and Bolivian families refused to participate.

\section{Measures}

Friendship Quality Scale (Bukowski, Hoza \& Boivin, 2004) was used to assess children's perception of their friendship quality. It consists of 22 items with responses on a 4-point Likert scale ranged from 1 (not at all) to 4 (very much). It is composed by 5 sub-scales:

- Intimacy: 5 items (e.g. I feel happy when I am with my friend). Cronbach's $\alpha$ is about 0.59 in both countries.

- Security: 5 items (e.g. If I have a problem at school or at home, I can talk to my friend about it). Cronbach's $\alpha$ is about 0.51 in both countries.

- Help: 5 items (e.g. my friend helps me when I am having trouble with something). Cronbach's $\alpha$ is about 0.64 in both countries.

- Companionship: 3 items (e.g. "My friend and I spend all our free time together). Cronbach's $\alpha$ is about 0.56 in both countries.

- Conflict: 4 item (e.g. I can get into fights with my friend). Cronbach's $\alpha$ is about 0.70 in both countries.

Drawing task was accomplished by asking children to draw themselves together with a friend. The exact request given to the children was: "Draw yourself with a friend". More precisely we asked children to refer to a friend who could be a classmate or not, and to identify his/her name. Children did not have any restriction about colors and/or kind of pen to use or time to complete the task. However, no child spent more than 45 minutes.

Two researchers independently coded each of the drawings using the coding system developed by Bombi and Pinto (1993, 2000; Bombi et al., 2007). A third coder intervened in cases of disagreement; the inter-judgment agreement in our study ranged between $78 \%$ and $91 \%$. The three coders, two PhD students and one Post-Doc researchers in Developmental Psychology, had all received a specific training with this coding system and undertook a specific practice before coding children' drawings.

The whole coding system included other scales that we did not include in the present study, such as the global value of the child and his/her friend and the emotional climate. In this study we have focused on:

The Scale of Similarity (possible range: $0-8$; range 2-8; $M=5.58, S D=1.46$ ) considers four indicators (or sub-scales): each one is scored as heavily different (0), lightly different (1), and negligible or no difference (2).

- (S1) Height (i.e., the linear distance between the head and the feet, the difference is null or negligible when the height is the same or the height of the smallest figure reaches at least the nose of the tallest one ( reaches any point included between the nose and the lowest part of the head of the tallest figure ( $($ core $=1$ ), and heavy when the height of the smallest figure does not reach the lowest part of the head of the tallest figure $($ score $=0$ ).

- (S2) Posture: To assign a score, we consider whether the two figures have the same posture or not and appear with the same or a different orientation (globally and/or in certain parts of the body). The difference in posture is considered heavy when the difference is very stressed; light when it concerns only the arms or legs, the head, and the bust; negligible when it concerns the above-mentioned parts but is less stressed; and null when the figures have the same posture or show very few differences.

- (S3) Body: First, we count the body parts that can be identified in each figure. We then 
attributed the scores of 2 when we find $0-1$ (simple drawings: it is possible to identify 10 parts) or 1-2 differences (complex drawings: it is possible to identify at least 11 parts), 1 when we find 2-3 (simple drawings) or 3-4 differences (complex drawings), and 0 when we find 4 or more differences (simple drawings) or 5 or more (complex drawings).

- (S4) Attribute: The score of this sub-scale is based on the number of differences identified in 11 categories: clothes, shoes, socks, hat, scarf, gloves, belt, glasses, jewels, and objects. Presence/absence, shape, articulation, and colour are considered as differences. We attributed the scores of 2 when we find 0-1 (simple drawings: up to 3 categories) or 1-2 differences (complex drawings: at least 4 categories), 1 when we find 2-3 (simple drawings) or 3-4 differences (complex drawings), and 0 when we find 4 or more differences (simple drawings) or 5 or more (complex drawings).

The Scale of Cohesion (possible range: $0-6$; range $0-5 ; M=1.53, S D=1.33$ ) considers six indicators (or sub-scales): each one is scored as absent (0) or present (1):

- (C1) Glance: The figure is scored 1 when he/she is able to perceive the head and/or major part of the body of the other figure; otherwise the score is 0 .

- (C2) Approaching: The figure is scored 1, when his/her position suggests a reduction of the space between him-/herself and the second figure; otherwise the score is 0 .

- (C3) Coordinate activity: The coding system considers two steps. In the first step, we establish whether or not each of the figures is involved in one action. In the second step, we evaluate whether these actions are coordinated among the figures (1) and/or are independent (0).

- (C4) Nearness: To obtain a score of 1, the two figures have to be at least "at hand"; otherwise the score is 0 .

- (C5) Common Area: The figures are considered to be in a common area (1) when they are together in a definite place or when the space that surrounds the figures is delimited by some elements that mark the borders. Otherwise the score is 0 .

- (C6) Union: Two figures are considered a unit (1) when they are directly or indirectly linked. Otherwise the score is 0 .

The Scale of Distance (possible range: 0-6; T 1: range 0-5; $M=1.63, S D=1.35$ ) considers six indicators (or sub-scales): each one is scored as absent (0) or present (1):

- (C1) Looking Away: The figure is scored 1 when he/she does not look at the other; otherwise the score is 0 .

- (C2) Moving away: The figure is score 1 when he/she position suggests an increase of the space between him-/herself and the second figure; otherwise the score is 0 .

- (C3) Independent Action: The coding system considers two steps. In the first step, we establish whether or not each of the figures is involved in one action. In the second step, we evaluate whether these actions are coordinated among the figures $(0)$ and/or are independent (1).

- (C4) Remoteness: The score 1 is assigned when the two figures are not "at hand"; otherwise the score is 0 .

- (C5) Individual Space: The score 1 is assigned when the figures are not in a common area or they are not together in a definite place or when the space that surrounds them is delimited by elements that mark the borders; otherwise the score is 0 .

- (C6) Separation: Two figures are not considered a unit (1) when they are directly or indirectly no-linked; otherwise the score is 0 .

\section{Data Analysis}

Analysis of Variance was used to explore the differences between countries for friendship quality, similarity, cohesion and distancing through. To explore the moderation effect of the country on the relationship between pictorial friendship's characteristics and friendship quality was used the 
Factorial Analysis of Variance. More precisely, in order to test the moderation effect of the country, in each Factorial Analysis of Variance, the positive and/or negative friendship quality as dependent Volume 3, 2012 variables and the country and the pictorial friendship's characteristics (in terms of total scale score and also single indicator scores) as fixed factors or main effects were used. Besides, the interaction among main effects, that is the country and indicators of pictorial friendship characteristics was considered.

\section{Results of Research}

\section{Country Differences in Regard to Study Variables}

Pictorial friendship's characteristics. As seen in Table 1 Italian children drawn themselves and their friend with more similarity $[\mathrm{F}(1.94)=6.65 ; \mathrm{p}<.002]$ and with less distancing indicators $[\mathrm{F}(1.94)=10.81 ; \mathrm{p}<0.002]$ than Bolivian children; no significant differences were found respect to the cohesion's characteristics.

Friendship Quality. Also for the friendship quality there are differences between Italian children and Bolivian children. Specifically, the perception of intimacy $[F(1.97)=23.52 ; p<0.0001]$, helping $[F(1.98)=6,85 ; p<0.010]$, and companionship $[F(1.97)=7.35 ; p<0.008]$ is higher among Italian children than Bolivian children, while the perception of conflict is greater among Bolivian children than Italian children $[\mathrm{F}(1.98)=7.87 ; \mathrm{p}<0.006]$ (See Table 2$)$.

Table 1. Similarity Cohesion and Distance by country differences: means (M) and standard deviations (SD).

\begin{tabular}{|c|c|c|c|c|c|c|c|c|c|}
\hline & \multicolumn{3}{|c|}{ Italians } & \multicolumn{3}{|c|}{ Bolivians } & \multirow{2}{*}{$F$} & \multirow{2}{*}{$d f$} & \multirow{2}{*}{$\begin{array}{c}\text { Sig. } \\
\text { (2-tails) }\end{array}$} \\
\hline & $M$ & SD & $\mathrm{N}$ & M & SD & $\mathrm{N}$ & & & \\
\hline Similarity & 6.60 & 1.09 & 55 & 5.90 & 1.54 & 40 & 6.65 & 93 & 0.002 \\
\hline Cohesion & 1.61 & 1.11 & 55 & 1.31 & 1.12 & 40 & 1,68 & 94 & 0.06 \\
\hline Distance & 0.25 & 0.673 & 55 & 0.78 & 0.921 & 40 & 10.81 & 94 & 0.002 \\
\hline
\end{tabular}

Table 2. Features of Friendship Quality by country differences: means (M) and standard deviations (SD).

\begin{tabular}{|c|c|c|c|c|c|c|c|c|c|}
\hline & \multicolumn{3}{|c|}{ Italians } & \multicolumn{3}{|c|}{ Bolivians } & \multirow{2}{*}{$F$} & \multirow{2}{*}{$d f$} & \multirow{2}{*}{$\begin{array}{c}\text { Sig. } \\
\text { (2-tails) }\end{array}$} \\
\hline & M & SD & $\mathbf{N}$ & M & SD & $\mathrm{N}$ & & & \\
\hline Intimacy & 17.19 & 1.09 & 55 & 14.58 & 1.55 & 40 & 23.52 & 93 & 0.001 \\
\hline Help & 15.46 & 1.2 & 55 & 13.8 & 1.13 & 40 & 6.85 & 94 & 0.01 \\
\hline Compan. & 9.79 & 0.684 & 55 & 8.62 & 0.932 & 40 & 7.35 & 94 & 0.008 \\
\hline Conflict & 7.15 & 1.31 & 55 & 8.89 & 1.12 & 40 & 7.87 & 94 & 0.006 \\
\hline
\end{tabular}

Interactions between Similarity, Cohesion and Distancing and Country Predicting Friendship Quality: Country Moderation Effect

At first, the factorial Analyses of Variance showed that there are some relationships between different levels of pictorial similarity and cohesion and friendship quality in Italian and Bolivian children. No difference was found respect to the levels of distancing and friendship quality between countries.

Considering Security, data showed significant differences based on the level of body similarity 
between friends in the drawings $[\mathrm{F}(2)=2.69 ; \mathrm{p}<0.05]$. No other difference between countries was found in the security scores $[F(2)=1.18 ; p=0.28]$.

Moderation effect of the country on the relation between body similarity and security was found $[F(2)=2.47 ; p<0.050]$. Specifically among Italian children, high levels of body differences are associated with a low level of security with friend (See Figure 1). Considering the Conflict, no significant difference was found between level of height similarity between friends in the drawings $[\mathrm{F}(2)=0.948 ; \mathrm{p}=0.39]$ and between countries $[\mathrm{F}(2)=0.122 ; \mathrm{p}=0.72]$.

Moderation effect of the country was found between height and friends conflict $[\mathrm{F}(2)=3.28$; $\mathrm{p}<0.05]$. Specifically among Bolivian children, height's similarity is associated with high level of friend conflict (See Figure 2).

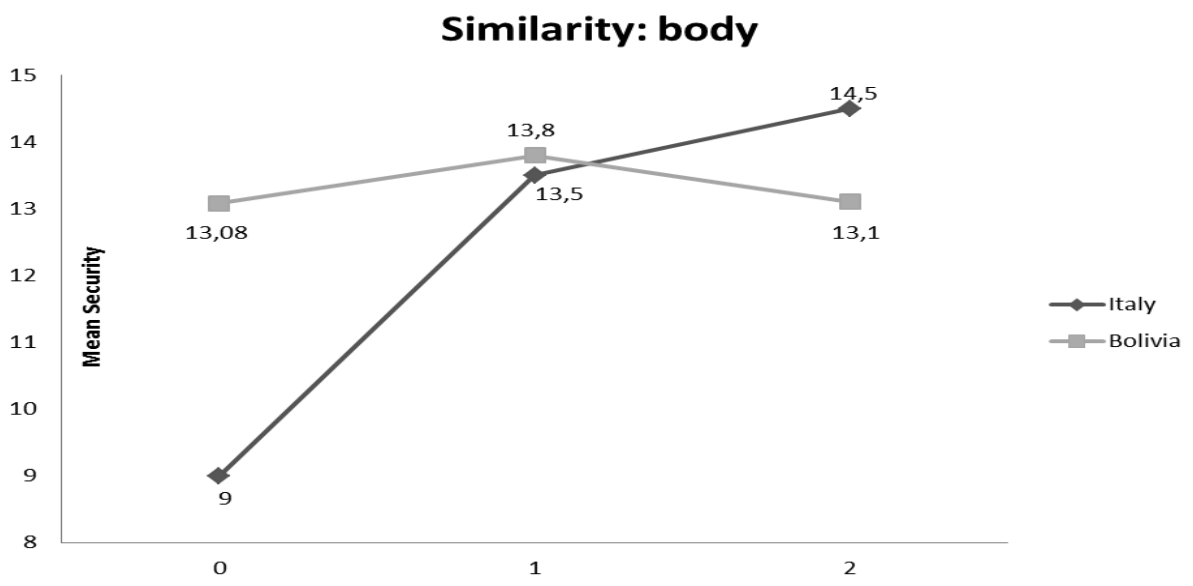

Figure 1: Country moderation effect between Similarity and Security.

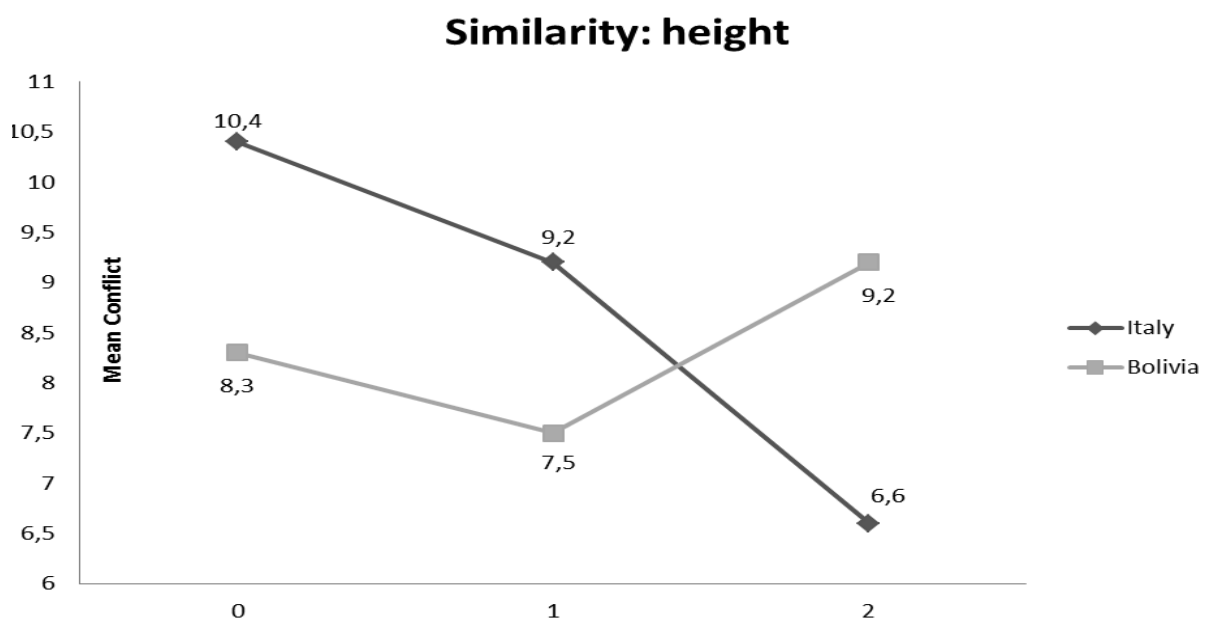

Figure 2: Country moderation effect between Similarity and Conflict.

The Intimacy was not different based on the presence/absence of glance between friends in the drawings $[\mathrm{F}(1.92)=2.83 \mathrm{p}=0.09]$. Difference between countries was found in the level of intimacy $[\mathrm{F}(1.92)=26.15 \mathrm{p}<0.05]$ (See Table 2). Moderation effect of the country was also found between glance and intimacy $[\mathrm{F}(2)=4.61 ; \mathrm{p}<0.05]$. Specifically among Italian children high level of glance are associated with high level of intimacy (See Figure 3).

Intimacy was also different considering the level of union between friends in the drawings $[\mathrm{F}$ $(1.92)=3.21 \mathrm{p}<0.07]$. Difference between country was found in the levels of intimacy [F $(1.92)=$ $16.08 \mathrm{p}<0.05]$ (See Table 2). Moderation effect of the country was also found between union and intimacy $[F(2)=4.68 ; p<0.05]$. Specifically among Italian children high level of union are associated with high level of intimacy. 


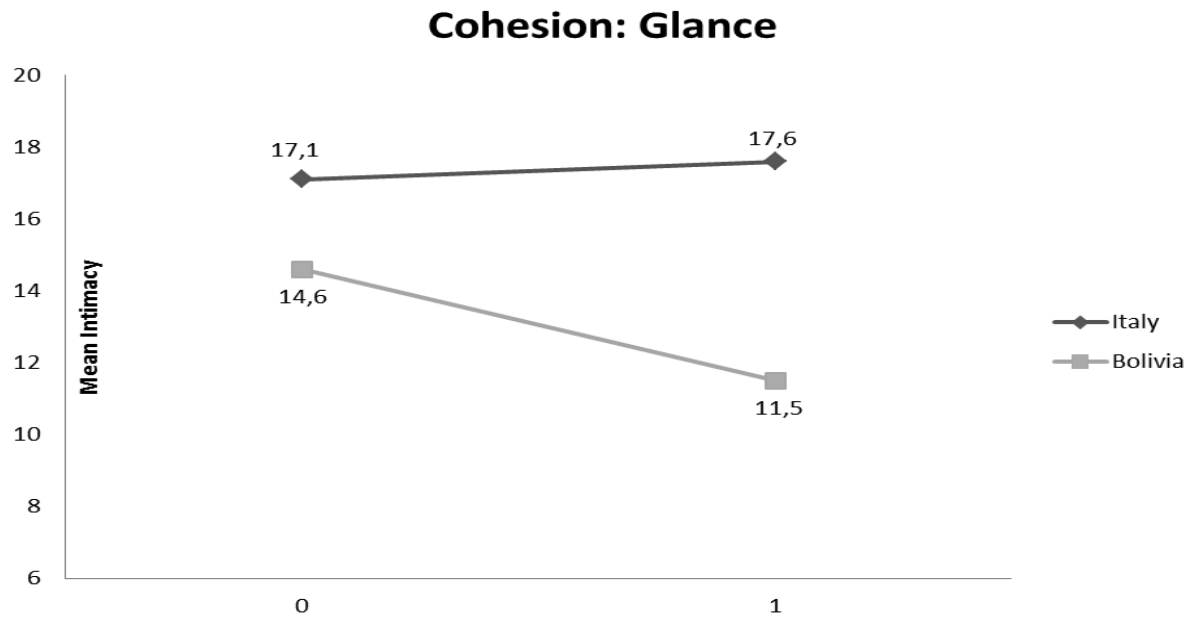

Figure 3: Country moderation effect between Cohesion and Intimacy.

Respect to the Conflict, no significant differences were found considering the presence/absence of coordinative activity in the drawings $[\mathrm{F}(1.93)=0.13 \mathrm{p}=0.91]$. Difference among countries was found in the level of friend conflict $[F(2)=4.68 ; p<0.05]$ (See Table 2). Moderation effect of the country was also found between coordinative activity and friend conflict $[F(2)=3.33 ; p<0.05]$. Among Bolivian children a presence of coordinative activity is associated with high level of friend conflict (See Figure 4).

\section{Cohesion: Coordinate Activity}

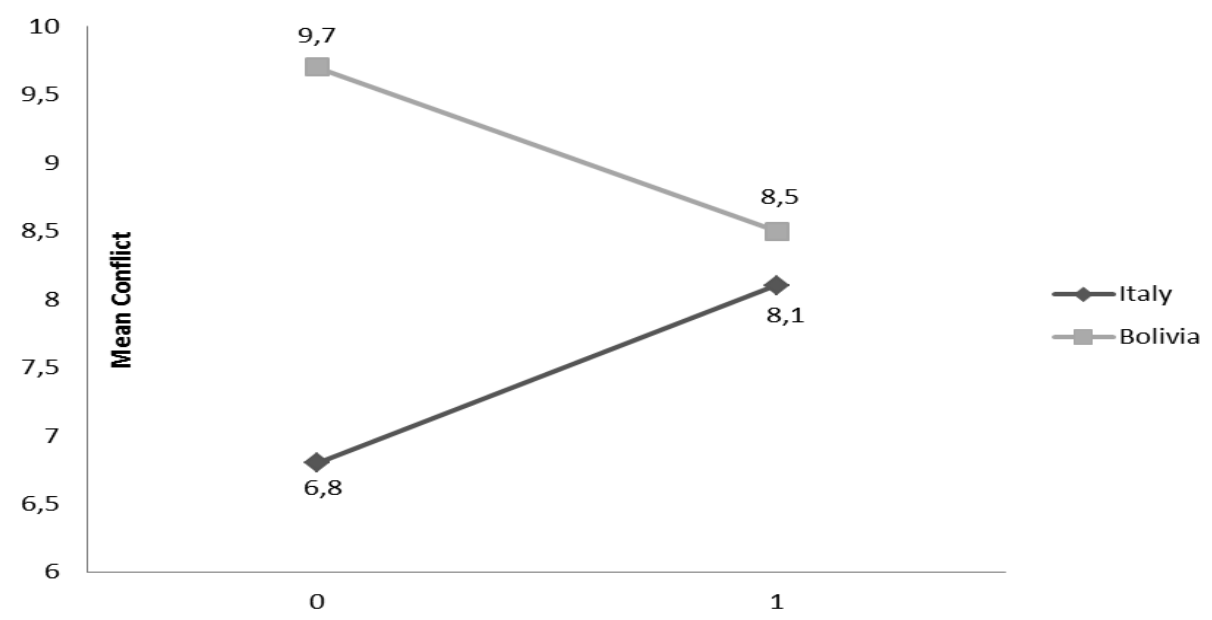

\section{Figure 4: Country moderation effect between Cohesion and Conflict.}

\section{Discussion}

The main purpose of this research was to study children friendship across different countries.

Specifically, the first objective was to describe how children represent themselves with their best friend, in terms of similarity, cohesion and distance according to the cross-national differences.

In keeping with the dichotomy between individualistic (Italy) and collectivistic (Bolivia) general sociological orientation more similarity and cohesion and less distancing between Bolivian children than Italian children were expected. Nevertheless, according to the two school systems, the opposite was expected, that is that children who are educated by their teachers accordingly the principles of prosocial behavior as the Italian ones are also more likely that their Bolivian mates to perceive themselves very similar and less distant from their friends. 
It was found support for the second hypothesis: Italian children perceive themselves and their friends more similar respect to Bolivian children.

Moreover Italian children tend to accentuate less distancing from their friends than Bolivian children. Despite the individualistic orientation of the Italian society, we can assume that these findings reflect the Italian school system' values and the teacher's educational style. The Italian school system is in fact based on an authoritative educational style, in which values, such as the peer collaboration and mutual support are sought and disseminated through teaching and learning (Petter 2004; Bonino \& Reffieuna, 2007). The substantial importance attributed to the team-class working and to the sharing of the abilities between mates by the Italian teachers may have contributed to the fact that the children feel themselves more similar and less distant from their friends than Bolivian children. Despite the return in the recent years to teaching and learning processes more individualistic, the values taught to the children are rooted enough to influence their perception of friendship. Furthermore, although the change in educational system that Bolivia is undertaking during the most recent years, the Bolivian school system seems not to have yet reached the level of Italian school system in promoting social relationships among children.

Moreover culture has a great influence on the development of children's representational capacities (Tramonti, 2005). In Italy, children are stimulated to draw, both directly and indirectly. In others countries, such as in Bolivia, teachers give strict directions to their pupils which block children's fantasy. Generally, drawing is neglected in favour of others forms of art, such as dance and music. So it can be probable that drawing is almost unknown to the Bolivian children and that they have had more difficulty in drawing themselves with similar aspects to their best friend than Italian children.

The presence of similarity between Italian friends and the presence of less indicators of distancing is consistent with the literature mentioned above. Similarity is a very basic feature of friendship and it is present in children's drawing (Bombi \& Pinto, 1994; Bombi et al., 1997). As research stated (Hartup, 1979; Popp, Laursen, Kerr, Stattin, \& Burk, 2008) during middle childhood children choice their friends on the basis of factual similarities: they search for friends mainly of the same sex, age and with the same physical characteristics. These assumptions are confirmed by the present study. Moreover the fact that Italian children also express through their drawings a decrease of physical distancing also confirmed that during middle childhood children search for more closeness and physical proximity with the friend (Berndt, 1981). The presence of a less degree of physical distancing between friends will contribute over time to a decrease of psychological distance that it will allow to the children to build a close and intimate friendship (Berndt, 2002).

Then it was investigated the possible differences between Italian and Bolivian children respect to the perception of their friendship quality. According to the different education styles adopted in Italy and Bolivia school system differences between Italian and Bolivian friends were found, but in favour of the Italian children. Italian children in fact are more likely to construct and to perceive high positive friendship quality in terms of intimacy, help and companionship with the best friends while Bolivian children are more likely to perceive friend conflict. These findings probably reflect again the educational styles adopted in the Italian country. The fact that Italian children are usually involved in sharing learning and personal experiences during the primary school and that in the class are more valued the cohesion and integration of the members than in Bolivia could be the explanation of these different findings. Although the contextual influence can not exclude, it is possible that Bolivian children are not yet able to reflect on friendship as on a relation characterized by intimate and close aspects and to consider their friends as a person with whom share and mutually exchange help and confidence and not only activities and material exchanges. Moreover in Bolivia the children are around forty for each class, about the double respect to the Italian class, and so the building and the maintaining of a close friendship can be more difficult.

Finally the presence of a possible moderating effect of country differences in the relationship between pictorial characteristics of friendship and the quality of these relationships perceived by the children was analyzed. Possible differences in these associations respect to children country differences were assumed. Among Italian friends low level of similarity between friends was found, such as differences in body and height are associated with less security and high conflict in friendship. These results are consistent with the expectations. Since that positive pictorial characteristics of the 
friendship and positive features of friendship quality are aspects of the same phenomenon a positive association between them was expected. The search for similarity, proximity and closeness in friendship is typical of the middle childhood (Berndt, 2002). This tendency whether really present may have three different but not alternative explanations. First, selecting friends perceived as similar to themselves might represent an advantage within a intimate and intense relationship (Aboud \& Mendelson, 1996). Second, emphasizing in one's own mental representation a similarity with the friend might be reassuring (Maccoby \& Jacklin, 1987). Finally, the partners in an intimate and supportive relationship might really become more similar because of their participation in a specific friendship (Popp et al., 2008).

These positive association were not found in Bolivian children. In fact regards Bolivian children a high level of similarity, indicated by similar height among friends, is associated with friend conflict. These results probably could be consistent with the fact that "too much similarity" between friends could represent a risk of losing personal identity (White, Speisman, Costos \& Smith, 1987). The loss of own identity and uniqueness could be the reason of a major occurrence of conflict episodes between friends. This finding further emphasized the need of the children to feel themselves similar enough to other persons while at the same time different enough to maintain their personal individuality (Bombi et al., 1997).

Also respect to the cohesion, the presence of glance and union is associated with positive friendship quality among Italian children. These findings highlighted the importance of mutual actions between friends, such as to look each other and the proximity with the other in order to establish a close friendship (Bombi \& Pinto, 2004). To look someone is an affiliative act observed in ethological studies on social behaviour (Strayer, 1980) and has a regulatory effect on interaction. Besides, the union between two figures is indicative of intimacy and sharing (Bombi \& Pinto, 1994).

Conversely in Bolivian children the presence of a coordinative activity with friend is associated with friends conflict. Probably this finding emphasizes one more time the scarce presence of psychological aspects in Bolivian children's friendship with respect to Italian children's friendship. It seems reasonable that the friendship of Bolivian children is not still enhanced by important psychological dimensions, such as intimacy, help, confidence and trust (Fonzi \& Tani, 1996) but it is still characterized by the transitory sharing of activities, which could also create some episodes of conflict and discordance between friends (Berndt, 2002). In this regard, the early propensity, which is already expressed in the middle childhood, to establish a very intimate and close friendship, was assumed to be a peculiarity of the Italian society: in other populations investigated, it would arise only from the adolescence age (Tani et al., 2005).

\section{Conclusions}

This study has several limitations, starting with the limited size of the group of participants. The small number of our participants did not allow to conduct separate analyses by gender and age. Another critical issue is that it is a cross sectional research design and this precludes from investigating the long-term patterns of the above-mentioned relationships. The next step in this line of research is to investigate these associations over a longer period of time. Moreover only children ratings and instruments were used: using a combination of children parents and teacher children friendship assessments could offer the most practical assessments for more global vision of the phenomenon.

Furthermore, although the method of exploring children's friendship by drawing appears more adequate than others among this age group and despite the methodological severity used in the coding of drawings, the idea that some biases might have been introduced in the process of coding children's drawings can not fully exclude. Finally, the children were asked to draw themselves with a friend. Although children were asked to identify the name of the drawn friend, the possibility that they represented an ideal instead of a real friendship can not excluded.

Despite these and other limitations, this study represents an important contribution to the cross-national investigation of friendship characteristics during middle childhood because - to our knowledge - it is the first study that has explored the association between pictorial friendship's indicators and friendship quality.

Although friendship is a relationship present in all countries and even though its basic aspects 
are universal, the external features that characterized it can vary culturally. The friendship practice required the acquisition of abilities and competencies specific to the context which are characterized by different relational styles that distinguish different social environment.

The study has been demonstrated that the perception of children's friendship is not so similar among different countries. Friendship relations, as all the other relationships, do not build on their own, but they are part of the reality of the everyday life in which the social actor lives. This has also highlighted that not always the children's friendship perception reflect the social context's orientation (individualistic vs collectivistic) in which they live and grown, but it may also reflect mostly the educational style and the values promoted and disseminated by the school system.

In conclusion, some environmental conditions, such as the school system during the years of primary school and the importance assumed by certain principles over time, influence the children social development and their friendship at least during middle childhood. It is in fact in the school that children learn some essential aspects for building and maintaining social relationships and friendships such as the cooperation, social and emotional comparison, and empathy.

Children social development is not independent from culture, meant in broad terms, and the present study gives a particularly significant contribution in this field of research.

\section{References}

Aboud, F. E., \& Mendelson, M. J. (1996). Determinants of friendship selection and quality: developmental perspectives. In W. M. Bukowski, A. F. Newcomb, \& W. W. Hartup (Eds.), The company they keep. Friendship in childhood and adolescence (pp. 87-114). Cambridge: Cambridge University Press.

Adamopoulos, J., \& Bontempo, R. N. (1986). Diachronic universals in interpersonal structures: Evidence from literary sources. Journal of Cross-Cultural Psychology, 17,169-189.

Argyle, M. (1986). Rules for social relationships in four cultures. Australian Journal of Psychology, 38, 309-318.

Berndt, T. J. (1981). Effects of friendship on prosocial intentions and behavior. Child Development, 52, 636643.

Berndt, T. J. (1982). The features and effects of friendship in early adolescence. Child Development, 53, $1447-1460$

Berndt, T. J. (2002). Friendship quality and social development. Current Directions in Psychological Science, $11,7-10$.

Berndt, T. J., Hawkins, J. A., \& Jiao, Z. (2005). Influences of friends and friendships on adjustment to junior high school. Merrill-Palmer Quarterly, 45, 13-41.

Berscheid, E., Snyder, M., \& Omoto, A. M. (1989). The Relationship Closeness Inventory: Assessing the Closeness of Interpersonal Relationships. Journal of Personality and Social Psychology, 57 (5), $792-807$.

Bishop, J. A., \& Inderbitzen, H. M. (1995). Peer acceptance and friendship: An investigation of their relation to self-esteem. Journal of Early Adolescence, 15, 476-489.

Bombi A.S. (1993) L'amicizia fra bambini. In A.S. Bombi, \& G. Pinto (a cura di), I colori dell'amicizia (pp. 13-45). Bologna, IT: Il Mulino.

Bombi, A. S., \& Pinto, G. (1993). I colori dell'amicizia. Bologna, IT: Il Mulino.

Bombi, A. S., \& Pinto, G. (1994). Making a dyad: cohesion and distancing in children's pictorial representation of friendship. British Journal of Developmental Psychology, 12 (4), 563-575.

Bombi, A. S., \& Pinto, G. (2000). Le relazioni interpersonali del bambino. Roma, IT: Carocci.

Bombi, A. S., Pinto, G., \& Cordioli A. (1997). Similarity of Friends in Three Countries: A Study of Children's Drawings. International Journal of Behavioral Development, 2 (4), 453-469.

Bombi, A. S., Pinto, G., \& Cannoni, E. (2007). Pictorial assessment of interpersonal relationships (PAIR). An analytic system for understanding children's. Firenze, IT: Firenze University Press.

Bonino, S. \& Reffieuna, A. (2007). Psicologia dello sviluppo e scuola elementare. Dalla conoscenza all'azione. Firenze, IT: Giunti Editore. 
Bukowski, W. M., Hoza, B., \& Boivin, M. (1994). Measuring friendship quality during pre- and early adolescence: The development and psychometric properties of the Friendship Quality Scale. Journal of Social and Personal Relationships, 11, 474-484.

Cassibba, R., Balenzano, C., Elia, L. (2008). Essere amici aiuta a risolvere i conflitti?. Età Evolutiva, 91, 46-56.

Clark, M. L., \& Drewry, D. L. (1985). Similarity and Reciprocity in the Friendships of Elementary School Children. Child Study Journal, 15(4), 251-264.

Duck, S. (1988). Handbook of Personal Relationship. Chirchester: Wiley.

Festinger, L. (1954). A theory of Social Comparison Processes. Human Relations, 7, 117-140.

Fonzi, A., \& Tani, F. (1996). Dall'infanzia alla preadolescenza: continuità e discontinuità nello sviluppo dei legami di amicizia. Età Evolutiva, 54, 89-94.

Furman, W. (1996). The measurement of friendship perceptions: Conceptual and methodological issues. In W. M. Bukowski, A. F. Newcomb, \& W. W. Hartup (Eds.), The company they keep: Friendship in childhood and adolescence (pp. 41-65). New York: Cambridge University.

Hartup, W. W. (1979). The social worlds of childhood. American Psychologist, 34, 944-950.

Hartup, W. W. (1989). Social relationships and their developmental significance. American Psychologist, 44, 120-126.

Hartup, W. W. (1996). The company they keep: Friendships and their developmental significance. Child Development, 67, 1-13.

Hartup, W. W., \& Stevens, N. (1997). Friendship and adaptation in the life course. Psychological Bulletin, $121,355-370$.

Hofstede G. (1980). Culture's Consequences: International Differences in Work- Related Values. London, UK: Sage.

Hofstede G. (1991). Cultures and Organization: Software of the Mind. London, UK: McGraw Hill.

Inghilleri P. (2009). Psicologia culturale. Milano: IT, Raffaello Cortina Editore.

Kelley, H. H., Berscheid, E., Christensen, A., Harvey, J. H., Huston, T. L., Levinger, G., McClintock, K. E., Peplau, L.A., \& Peterson, D. R. (1983). Close Relationships. New York, S. Francisco: W. H. Freeman.

Krappmann, L. (1996). Amicitia, druijba, shin-yu, philia, freundschaft, friendships: On the cultural diversity of a human relationship. In W.M. Bukowski, A.F. Newcomb, W.W. Hartup (Eds), The company they keep: Friendships in childhood and adolescence, pp. 19-40, Cambridge University Press, New York.

Ladd, G. W., Kochenderfer, B. J., \& Coleman, C. C. (1996). Friendship quality as a predictor of young children's early school adjustment. Child Development, 67, 1103-1118.

Ladd, G. W., \& Price, J. M. (1987). Predicting children's social and school adjustment following the transitions from preschool to kindergarten. Child Development, 58, 1168-1189.

Laursen, B. \& Hartup, W. W. (2002). The origins of reciprocity and social exchange in friendship. Social Exchange in Development. New Directions for Child and Adolescence Development, 95, 27-40.

Maccoby, E. E., \& Jacklin, C. N. (1987). Gender segregation in childhood. In H.W. Reese (Eds.), Advances in child development and behavior, Vol. 20 (pp. 239-287). New York, US: Academic Press.

Martin, C.L, \& Fabes, R.A. (2001) The stability and consequences of young children's same-sex peer interactions. Developmental Psychology, 37, 431-446.

Petter, G. (2004). Il bambino va a scuola, Bologna, IT: Il Mulino.

Popp, D., Laursen, B., Kerr, M., Stattin, H., \& Burk, W. J. (2008). Modelling homophily over time with an Actor-Partner Interdependence Model. Developmental Psychology, 44, 1028-1039.

Rabaglietti, E., Vacirca, M.F., Zucchetti, G., \& Ciairano, S. (2012). Similarity, Cohesion, and Friendship Networks among Boys and Girls: A one-year follow-up study among Italian children. Current Psychology, (In Press).

Rose, A. J., \& Smith, R. L. (2009). Sex difference in peer relationships. In K. H. Rubin, W. M. Bukowski, \& B. Laursen. (Eds.), Handbook of peer interactions, relationships and group (pp. 379-383). New YorkLondon: The Guilford Press. 
Emanuela RABAGLIETTI, Maria Fernanda VACIRCA, Giulia ZUCCHETTI, Carmen CAMACHO, Silvia CIAIRANO. Similarity, Cohesion, Distancing and Friendship Quality among Italian and Bolivian Boys and Girls: A Cross National Comparison

Selman, R. L. (1981). The child as a friendship philosopher. In S. R. Asher \& J. M. Gotman (Eds). The development of friendship. Cambridge: Cambridge University Press.

Strayer, F. F. (1980). Child ethology and the study of preschool social relations. In H. C. Foot, A. J. Chapman \& J. R. Smith (Eds). Friendship and social relations in children. New York: Wiley.

Sullivan, H. S. (1953). The interpersonal theory of psychiatry. New York: Norton.

Tani, F., Rossi, S., Smorti, M. (2005). I criteri di scelta degli amici nell'infanzia e nell'adolescenza. Un'indagine sulle caratteristiche di personalità. Età Evolutiva, 1, 33-43.

Tomada, G., Schneider, B. H., de Domini, P., Greenman, P. S., \& Fonzi, A. (2005). Friendship as a predictor of adjustment following a transition to formal academic instruction and evaluation. International Journal of Behavioral Development, 29, 314-322.

Tramonti, F. R. (2005). The evolution of children's representational capacities: A cross-cultural study. Human Evolution, 20 (1), 47-54.

Various Authors (2010). A cochabamba me voy. Djario Boliviano. Retrieved 15/01/ 2011. from http://www. acochabambamevoy.org/

White, K. M., Speisman, J. C., Costos, D., Smith, A. (1987). Relationship maturity: a conceptual and empirical approach. Contributions to human development, 18, 81-101.

Whiting, B. B., \& Edwards, C. P. (1988). Children of different worlds. Cambridge, MA: Harvard University Press.

Advised by Irena Gailiene, SMC "Scientia Educologica”, Republic of Lithuania

Received: May 16, 2012

Accepted: June 15, 2012

\begin{tabular}{|c|c|}
\hline Emanuela Rabaglietti & $\begin{array}{l}\text { PhD, Researcher, Department of Psychology, University of Turin, Via Verdi 10, Turin, } \\
\text { 10100, Italy. } \\
\text { E-mail: emanuela.rabagliett@@unito.it }\end{array}$ \\
\hline Giulia Zucchetti & $\begin{array}{l}\text { PhD Student, Department of Psychology, University of Turin, Via Verdi 10, Turin, } 10100 \text {, } \\
\text { Italy. } \\
\text { E-mail: giulia.zucchetti@unito.it }\end{array}$ \\
\hline Maria Fernanda Vacirca & $\begin{array}{l}\text { PhD, Researcher, Department of Psychology, University of Turin, Via Verdi 10, Turin, } \\
\text { 10100, Italy. } \\
\text { E-mail: mariafernanda.vacirca@unito.it }\end{array}$ \\
\hline Carmen Camacho & $\begin{array}{l}\text { Researcher, University of Tarija, Bolivia } \\
\text { E-mail: ccamachot@gmail.com }\end{array}$ \\
\hline Silvia Ciairano & $\begin{array}{l}\text { Full Professor, Department of Psychology, University of Turin, Via Verdi 10, Turin, } 10100 \text {, } \\
\text { Italy. } \\
\text { E-mail: silvia.ciarano@unito.it }\end{array}$ \\
\hline
\end{tabular}

